La noticia narco en la Argentina. El imaginario social promovido por el diario Clarín en 2016 Fernanda Victoria Collinao Improntas de la historia y la comunicación (N. ${ }^{\circ}$ ), e042, 2020 ISSN 2469-0457 | https://doi.org/10.24215/24690457eo42 http://perio.unlp.edu.ar/ojs/index.php/improntas FPyCS | Universidad Nacional de La Plata La Plata | Buenos Aires | Argentina

\title{
La noticia narco en la Argentina
}

\section{El imaginario social promovido por el diario Clarín en 2016}

\section{Narcos's news in Argentina \\ The social imaginary projected by Clarin in 2016}

\section{Fernanda Victoria Collinao}

fernandacollinao@hotmail.com

https://orcid.org/0000-0003-1299-528X

Facultad de Periodismo y Comunicación Social

Universidad Nacional de La Plata | Argentina

\section{Resumen}

Mediante el desbroce de las estrategias enunciativas utilizadas por la edición digital del diario argentino Clarín y del análisis de los recursos que ofrece el ciberperiodismo para la construcción de representaciones, la autora analiza el imaginario social que el diario digital construyó durante 2016 acerca de la situación de la Argentina con respecto al tráfico ilícito de clorhidrato de cocaína y propone repensar las formas de comunicar el narcotráfico en general y cuestionar la categoría género policial en materia periodística.

\section{Palabras clave}

narcotráfico, ciberperiodismo, imaginario social, Clarín

\section{Abstract}

Through the unveiling of the enunciative strategies used by the digital edition of the Argentine newspaper Clarin, and the analysis of the resources offered by cyberjournalism for the construction of representations, the authoress analyzes the social imaginary that the digital newspaper projected during 2016 about the situation in Argentina in relation to the illicit traffic of cocaine and invites to rethink the ways of communicating drug trafficking in general and questioning the category of police news in journalistic matters.

Keywords narcotraffic, cyberjournalism, social imaginary, Clarin 


\title{
La noticia narco en la Argentina
}

\section{El imaginario social promovido por el diario Clarín en 2016}

\author{
Por Fernanda Victoria Collinao
}

\section{Presentación}

La restricción en la oferta de estupefacientes debe ser entendida como un fenómeno que es atravesado por una multiplicidad de variables tales como el tipo de estupefaciente que se pretende reducir, las diferentes etapas de producción y de fabricación, la magnitud de las redes de narcotráfico, la diferenciación de roles dentro de las organizaciones y la forma en las que los estupefacientes son encubiertos y transportados. Estas, entre otras tantas cuestiones, si no son explicitadas correctamente pueden llevar a crear imaginarios sociales que, en ciertas ocasiones, son utilizados por los gobiernos para justificar políticas públicas que continúan promoviendo una anacrónica «guerra contra las drogas», mediante la cual se habilita, en nombre de la opinión pública, un mayor desarrollo de políticas punitivistas -o de «mano dura»- en la sociedad.

El narcotráfico se presenta como un tipo de delito complejo que, por operar en la clandestinidad, vuelve muy difícil la cuantificación de los daños que provoca, de los volúmenes de estupefacientes que administra y de las cantidades de dinero que genera -entre tantas otras de las vastas aristas que presenta el tema- y, justamente por ello, también resulta fácil la tergiversación de los datos y las informaciones que se brindan a las audiencias con pocos conocimientos sobre el tema.

Por tales motivos, la presente investigación -realizada en el marco de la tesis para la Maestría en Periodismo y Medios de Comunicación de la Facultad de Periodismo y Comunicación Social de la Universidad Nacional de La Plata, ${ }^{1}$ se ha interesado por entender cuáles son aquellos datos que el diario Clarín, en su versión digital, decidió presentar al lectorado durante 2016, año en el que inicia la gestión de Mauricio Macri, ${ }^{2}$ el primer presidente argentino que eligió como uno de sus ejes de gobierno «combatir al narcotráfico». ${ }^{3}$ 
En los últimos años, el Tráfico Ilícito de Drogas (TID) o Narcotráfico se ha convertido en uno de los principales retos para la seguridad, la salud y el bienestar de la humanidad. Por ello, constituye una cuestión sobre la que los Estados, basándose principalmente en los tres tratados internacionales de fiscalización de drogas ${ }^{4}$ propios de la Organización de Naciones Unidas (ONU), comienzan a tomar medidas específicas tendientes a reducir la oferta y la demanda de drogas, a mejorar los contextos socioeconómicos de sus habitantes y a evitar la penetración del crimen organizado.

En el presente artículo, se recogen los fundamentos conceptuales expresados en la «Declaración Política y Plan de Acción sobre cooperación internacional en favor de una estrategia integral y equilibrada para contrarrestar el Problema Mundial de las Drogas» (2009),5 que define al Problema Mundial de las Drogas (PMD) como «el cultivo, la producción, la fabricación, la venta, la demanda, el tráfico y la distribución ilícitos de estupefacientes y sustancias sicotrópicas, incluidos los estimulantes de tipo anfetamínico, la desviación de precursores y las actividades delictivas conexas» (p. 7). En este sentido, es importante recalcar que cada uno de los países tiene la responsabilidad de afrontar el PDM con un enfoque equilibrado, multidisciplinario, integral y basado en el respeto a los derechos humanos, lo cual debe ser traducido en políticas, en estrategias y en acciones internas que consideren las particularidades nacionales, que fortalezcan las instituciones del Estado y, sobre todo, que se centren en el bienestar del individuo.

La mención sobre el abordaje integral y equilibrado de la problemática se vuelve vital para estas líneas, ya que permite diferenciar las dos caras de un mismo fenómeno: la oferta y la demanda de estupefacientes. Visto desde la óptica de la oferta, el narcotráfico es un fenómeno relativo a la seguridad pública que opera a escala global y que, como toda empresa económica, tiene como principal fin el lucro. El hecho de constituirse como una actividad de tipo ilegal hace que las redes delictivas se encuentren en constante elucubración sobre nuevas estrategias y métodos innovadores que les permitan ocultar los estupefacientes y/o precursores químicos frente a los ojos de las autoridades de control para lograr la subsistencia de su negocio (Vázquez, 2011).

Al respecto, la «guerra contra las drogas», uno de los paradigmas prohibicionistas con más asidero a nivel mundial en la historia de la restricción del narcotráfico, promueve 
programas de erradicación de cultivos ilícitos, incautación de cargamentos de estupefacientes, y seguimiento, investigación y captura de grupos criminales y de sus respectivos líderes, constituyéndose en una estrategia sumamente militarizada (Rosen \& Zepeda Martínez, 2016). Esta política ha recibido múltiples críticas a nivel internacional, dado que solo se aboca a la reducción de la oferta de drogas y no considera, entre otros aspectos, la prevención y la asistencia de las poblaciones ni el impacto de la actividad económica en el medioambiente. Otro de los cuestionamientos apunta a la magnitud de los recursos económicos y humanos que se invierten a cambio de escasos o de nulos resultados, mientras queda a la vista que el tráfico ilegal de drogas continúa.

\section{Algunas referencias sobre Clarín}

La decisión de trabajar con el diario Clarín implicó desbrozar aquellas estrategias comunicacionales que el medio, en su versión digital, utilizó durante el primer año de gestión de CAMBIEMOS -alianza electoral, compuesta, principalmente, por los partidos Propuesta Republicana y Unión Cívica Radical, que le permitió a Mauricio Macri acceder a la presidencia- para crear un imaginario social referido al narcotráfico en la Argentina.

Desde sus orígenes, en 1945, el diario surge bajo la premisa de estar siempre a la vanguardia tecnológica, a fin de que la circulación de sus publicaciones pueda darse de forma acelerada y ser recibida por la mayor cantidad de lectores/as posibles (Sivak, 2013). A lo largo de toda su historia, y en su carácter de actor político, el medio ha reafirmado una conducta pendular con los diferentes gobiernos de turno, siempre reconociendo la importancia de sostener un vínculo que le permitiera obtener ciertos beneficios. Entre ellas, no pueden soslayarse la importación de papel y/o maquinaria, así como la participación en la producción del insumo básico a partir de la sociedad conformada durante la última Dictadura cívico militar (1976-1983) con el Estado y con los diarios La Nación y La Razón para quedarse con la empresa Papel Prensa S.A. (Díaz, Giménez \& Passaro, 2008).

De este modo, la consolidación de la empresa, sustentada en el matutino, pudo lograr la expansión en determinados mercados, el otorgamiento de créditos y la adquisición de acciones en otras empresas del rubro comunicacional, amparándose en su «Declaración de principios», donde consigna la promoción al «fortalecimiento de las instituciones sociales que sustentan las garantías democráticas» (Grupo Clarín, 1995, en línea). 
El diario Clarín, siguiendo la tendencia mundial de aquellas empresas de comunicación pioneras en incursionar en las nuevas herramientas digitales que ofrecía Internet, presentó su propia versión digital en 1996. Esto le permitió expandir aún más su audiencia y erigirse como oferta innovadora en cuanto a su formato, gracias al uso de recursos propios del ciberperiodismo que, a su vez, puso a disposición de diferentes gobiernos y cuya utilización también se ha visto reflejada en la redacción de las publicaciones que se analizan en este trabajo.

$\mathrm{Al}$ respecto, no se puede soslayar la complejidad de las relaciones establecidas entre la empresa propietaria del medio examinado y el gobierno de Néstor Kirchner (2003-2007), quien designó como intermediario a Alberto Fernández, mediante el cargo formal de representante del Estado en Papel Prensa S. A. Merced a dicho vínculo, se administraron los beneficios que el Grupo Clarín recibió por ese entonces, entre ellos: la prórroga de las licencias de los canales de aire -que alcanzó a Canal 13-, el mantenimiento de la venta de los pliegos para las licencias de televisión por cable, una sustancial pauta publicitaria, ciertas primicias periodísticas y la fusión entre Cablevisión y Multicanal (Sivak, 2013).

Durante la primera presidencia de Cristina Fernández de Kirchner, precisamente, luego de la derrota en la elección legislativa de 2009, la mandataria tomó una serie de medidas que fueron fustigadas por el Grupo Clarín. Entre ellas, la apertura de licencias de cable antes congeladas y la sanción de la Ley 26.522 de Servicios de Comunicación Audiovisual (LSCA), que emplazaba a varios grupos multimediáticos, entre ellos a Clarín, a desprenderse de muchas de sus licencias (Fernández de Kirchner, 2019, p. 522). Héctor Magnetto, CEO de la empresa, se defendió apelando a la prensa internacional para expresar que la decisión gubernamental afectaba las libertades consagradas en la Constitución Nacional y ponía en juego a la democracia misma. Finalmente, en 2013, la Suprema Corte de Justicia de la Nación falló que la ley no atentaba contra la libertad de expresión.

Si bien Martín Sivak (2013) no aborda el período examinado en este trabajo, vale considerar su afirmación acerca de que «desde 2005, Clarín experimenta un retroceso en sus ventas. La caída obedece, en parte, al crecimiento de la lectura on line y, en parte, a la crisis global de los diarios impresos» (p. 408). El autor sostiene, además, que desde ese año el diario pasó a ser consumido, principalmente, por opositores al kirchnerismo, datos que serán clave a la hora de desbrozar el imaginario social presentado por el medio de comunicación, dado que es donde el concepto de «contrato de lectura», propuesto por Lucrecia Escudero Chauvel (1997), cobra especial sentido. Para la autora, entre medio 
de comunicación y lectorado surge una suerte de contrato fiduciario «que los medios de información escrita tratan de establecer con sus lectores de modo de hacer aceptar a priori la verdad del relato vehiculado, pero dejándole a posteriori la posibilidad de verificación» (Escudero Chauvel, 1997, s/p.).

En los prolegómenos de la coyuntura examinada, a través del Decreto de Necesidad y Urgencia 267 (2015), firmado por Mauricio Macri a pocos días de su asunción, Clarín logró que los artículos de la LSCA que afectaban sus intereses económicos fueran derogados. Así, a partir de enero de 2017, el Grupo no solo no se desprendió de ninguna de las empresas que administraba, sino que pudo comprar la empresa de telefonía móvil Nextel y, de esta forma, comenzar a ofrecer a su clientela el «cuádruple play», es decir, un combo de televisión, internet, telefonía fija y telefonía móvil (El Cronista, $18 / 04 / 2017)$.

Esta atención particular, pudo verse reflejada, durante 2016, en la estrategia de comunicación benevolente que el medio tuvo hacia el gobierno, en general, y hacia el narcotráfico, en particular, a partir de la promoción y la justificación de todas sus acciones y de la creación de un imaginario social cuyas características desarrollaremos a continuación.

\section{Aspectos teóricos-metodológicos}

El presente artículo se centra en el estudio del diario digital Clarín en su carácter de «actor político» con capacidad de influir en el proceso de toma de decisiones del sistema político (Borrat, 1989). En este sentido, la decisión de circunscribir la investigación solo a la versión digital se respalda en el trabajo de Arturo Barrios Puga (2013), quien sostiene que las versiones digitales de los diarios que también circulan en papel tienen un mayor aporte a la hora de conformar opinión pública, además de contar con mayor estabilidad en el tiempo y, por ende, una audiencia más amplia.

En relación con el interés que poseen los periódicos con respecto a influir en la sociedad, es menester presentar la definición de imaginario social como la representación de una especie de orden social en el cual cada elemento ocupa un espacio, y posee su identidad y razón de ser; es decir, se erige como una serie de «referencias específicas en el vasto sistema simbólico que produce toda colectividad 
y a través del cual ella se percibe, se divide y elabora sus finalidades» (Baczko, 1999, p. 28). De esta forma, el imaginario social, gracias a su tejido simbólico, opera a través de oposiciones de aspectos afectivos de la vida colectiva que pueden legitimar / invalidar, justificar / acusar, asegurar / desasegurar, incluir / excluir, entre otras acciones, con respecto al grupo (Baczko, 1999).

Para crear dicho imaginario, los medios de comunicación utilizan ciertas «estrategias enunciativas» (Verón, 2005, p. 205) que colaboran a crear sentido, tales como el principio de autoridad, de analogía y de concesión (Ducrot, 1989). Dichas estrategias son formuladas para un «destinatario genérico»-o público amplio-, al tiempo que se dirigen a diferentes auditorios: los paradestinatarios, los prodestinatarios y los antidestinatarios (Verón, 2005). ${ }^{6}$

En relación con las particularidades de los medios digitales, podemos mencionar que en estas versiones los diarios hacen uso de las oportunidades que ofrece Internet en lo que refiere al hipertexto, la interactividad, el multimedia y la personalización o actualización constante, cuatro aspectos específicos de la disciplina que conforman en la actualidad el ciberperiodismo (Masip y otros, 2010; García Sigman, 2015) y que colaboran para captar o para sostener a su lectorado, $y$, de esta forma, constituir imaginarios sociales.

Para mayores precisiones sobre las oportunidades que en este sentido ofrece Internet, en este trabajo se entiende por hipertexto a «la capacidad de interconectar diversos textos digitales entre sí, es decir, a la conjugación de textos y otros componentes multimediales (Salaverría \& Cores, 2005, p. 30), y por multimedialidad a «la habilidad que brinda el soporte digital de complementar en un mismo mensaje al menos dos de los siguientes elementos: sonido, imagen y texto (Salaverría \& Cores, 2005, p. 32).

En tanto, los distintos géneros periodísticos se consideran atendiendo a la propuesta de Concha Edo (2003), quien los define como

modelos concretos de creación lingüística que permiten presentar de forma adecuada y comprensible la información, la interpretación y la opinión, en cualquiera de las distintas variedades de medios de comunicación de masas, tanto escritos como audiovisuales o, en estos momentos, digitales (pp. 56-57, en Salaverría \& Cores, 2005, p. 146). 
De esta forma, el/la periodista tiene un modelo de enunciación con ciertos pasos y características específicas a seguir para la elaboración de una nota periodística, mientras que, para el lectorado, estos operan como patrones de interpretación u horizontes de expectativas con respecto a la información que busca consumir (Salaverría \& Cores, 2005).

En particular, la noticia de tipo policial requiere de la voz de fuentes oficiales, como los cuerpos provinciales de seguridad y las Fuerzas Federales y/o la Justicia, entre otras instituciones gubernamentales, debido a que son las primeras que llegan al lugar del hecho, que conocen de primera mano las actualizaciones y los hallazgos que permiten crear series informativas (Isla \& San Martín, 2009) y porque se vuelven fuentes privilegiadas a la hora de brindar cierto criterio de verosimilitud al relato presentado (Martini, 2002). En un sentido inverso, la falta de confianza en una institución puede abrir posibilidades de consulta a otros sectores de la sociedad. «La falta de credibilidad en la justicia ha posibilitado la mayor legitimidad de las voces de fuentes secundarias no oficiales en las noticias» (Martini, 2007, p. 9).

En lo que refiere específicamente al narcotráfico, en la publicación Coverage of Drug Traffiking and Organized Crime in Latin America and the Caribbean (2010), Tyler Bridges afirma: «Hay mucha cobertura, pero es muy superficial. Los reporteros policiales usualmente cubren la historia de droga» (p. 12). Se entiende, por esto, que para profundizar en la construcción de la noticia del narcotráfico -o noticia narco- es imperioso obtener un mayor entendimiento sobre la forma en la que se construye la información a publicar bajo el rótulo de «policial». En este marco, cobra especial sentido, por su precisión, el trabajo de Alejandro Isla y Raquel San Martín (2009), quienes desglosan ciertas características que hacen que los delitos se conviertan en sucesos noticiables:

- Novedad y negatividad: comparte con otros géneros la necesidad de que el hecho debe establecer una ruptura con la cotidianidad, pero debe presentar características negativas, en el sentido de comprometer la integridad física de una o varias personas, y hasta la misma vida, por una carga de violencia. Los autores resaltan, también, la puesta en juego de valores tales como la vida, el honor y la propiedad privada.

- Proximidad: se plantean situaciones que suceden en las cercanías de los hogares y, por ello, se intenta apelar a la empatía con el lectorado para aportar mayor verosimilitud a la publicación. 
- Jerarquía de los implicados: la exposición de una información adquirirá mayor cobertura al momento en el que un grupo vulnerable sea afectado por el delito. $\mathrm{Al}$ respecto, los autores resaltan la doble apelación con la que se evoca al Estado: por un lado, se le piden respuestas concretas y mayor eficiencia en sus acciones, por el otro, se lo etiqueta de corrupto y de ineficiente.

- Narratividad: los hechos delictivos pueden ser narrados en capítulos sucesivos, con intriga, descripción, personajes, suspenso y desenlace, una condición sumamente valorada en el discurso periodístico que pocos acontecimientos cumplen tan claramente. A partir de la tradición iniciada en los folletines, a fines del siglo XIX, el drama y las emociones vinculadas con los hechos delictivos agregan interés al relato mediático, dado que se erigen como un tipo de narrativa que presenta una importante receptividad en el público. En ciertas ocasiones, además, los/as periodistas asumen el rol de investigadores/as que marchan en forma paralela a la pesquisa oficial.

- Interés humano: la información sobre la vida privada de las víctimas y de los delincuentes, sus dramas y sus emociones, y las personas llevadas a situaciones límite, son la contracara de la información policial y judicial, presentada de manera racional. Se trata de un abordaje más utilizado en los delitos que se rotulan como «pasionales» -generalmente, vinculados con la violencia doméstica o familiar-, donde las notas revelan las historias de las personas involucradas en entregas sucesivas.

- Disponibilidad de datos estadísticos: las cifras, los valores y los porcentajes son sumamente requeridos a la hora de elaborar publicaciones periodísticas, dada la precisión científica que se busca generar. En palabras de Stella Martini (2007): «Las cifras del delito operan como la radiografía de la realidad» (p. 7).

- Series: según los autores, «los hechos delictivos suelen transformarse en "casos" o en series informativas que se prolongan en el tiempo, con una cobertura diaria que hace avanzar la historia y con rótulos que la hacen identificable para el lector».

- Sentido moral: en las noticias sobre el delito subyacen cuestiones morales, también vinculadas a oposiciones de aspectos afectivos de la vida colectiva como la idea de bien y mal, de culpa y castigo, de desviación y normalidad, entre otros.

La división geopolítica de las drogas tampoco queda exenta de la cobertura mediática: según el tema en el que la labor periodística decida focalizar y/o el criterio con el que se construya la agenda setting (Casermeiro de Peterson, 2003; Collinao \& Cristante, 2015), 
determinados países obtendrán cierta clase de «etiqueta» en el imaginario social. De este modo, como se menciona en Coverage of Drug Traffiking and Organized Crime in Latin America and the Caribbean (2010), según su relación con determinado estupefaciente los Estados tendrían una especie de clasificación: mientras Colombia siempre será sinónimo de producción de cocaína y de tierra natal de los principales cárteles de droga a nivel mundial, Paraguay será vinculado con plantaciones de cannabis y Bolivia con la de arbustos de coca, México tendrá un larga tradición de violencia extrema y de tráfico de armas, Afganistán será fuente de opio y de terroristas talibanes, y los Estados Unidos se erigirá como el principal consumidor de los más diversos estupefacientes.

El narcotráfico, como se ha mencionado en páginas precedentes, a través de la explicitación de la categoría de PMD, constituye un fenómeno que atraviesa las esferas sociales, culturales, económicas y políticas; no obstante, el periodismo continua abordando la temática como si se tratara de un hecho policial, en el que se relata el modus operandi de un caso en particular o se contabilizan las matanzas. En este marco, es necesario resaltar que el tratamiento del tema varía entre los diferentes países y que, según el grado de penetración que las redes criminales tengan en la sociedad, la libertad de prensa muchas veces se ve amenazada por la violencia que rodea el tema.

\section{Desbrozando el objeto de estudio}

Al comenzar a construir los datos, la investigación se abocó al estupefaciente «cocaína», dado que las drogas de síntesis -incluidas las nuevas sustancias psicoactivas-, la marihuana y el opio no atraviesan los mismos períodos de producción, de fabricación y de «estiramiento». ${ }^{7}$ En tanto, solo fueron consideradas aquellas informaciones publicadas en el marco de la oferta de estupefacientes y, en particular, las que tuvieron vinculación con las figuras penales consignadas en los artículos $5^{\circ}$ y $14^{\circ}$ de la Ley 23.737 de estupefacientes.

En tanto, si bien se es consciente de la larga historia del diario Clarín (sin ahondar en las posiciones ideológicas a favor o en contra de su influencia política y de su estructura económica) y del debate académico alrededor del tema, la decisión de circunscribir esta investigación solo a la versión digital de dicho periódico se basó en que, como se explicó por intermedio de los conceptos de Barrios Puga (2013), los diarios cuyas publicaciones circulan en versión física y digital poseen mayor capacidad de formar opinión pública y, justamente, de crear imaginarios sociales. Por tal razón, si bien de acuerdo al ranking 
de Alexa.com ${ }^{8}$ el diario digital Infobae -seguido del periódico objeto de estudio- es el medio que lidera las visitas en la web del rubro no ha sido considerado en este estudio. ${ }^{9}$

A fin de clarificar la forma de trabajo de la mencionada web, se consultó la investigación de Luis Alfonso Albornoz (2005), quien indica:

\begin{abstract}
Alexa.com elabora su clasificación de sitios web a partir de dos tipos de datos: el número de usuarios únicos (direcciones IP) que accede a una página web (denominado «alcance» o, en inglés, reach) y el número de páginas vistas (page views), es decir, el número total de veces que un usuario solicita una determinada dirección web (el número total de peticiones de URL diferentes en un sitio). Para evitar el incremento del número de páginas vistas por parte de motores automáticos, Alexa.com considera varias peticiones de la misma dirección por el mismo usuario en el mismo día como una sola página vista. De esta forma Alexa.com presenta a su ranking «como el índice más objetivo y fiable de Internet» que «refleja las preferencias y gustos de los usuarios a nivel mundial» (p. 29).
\end{abstract}

Para la cumplimentación del objetivo de investigación, se decidió aplicar, en primera instancia, la técnica de recolección de datos denominada clipping de medios. De esta forma, los artículos periodísticos que conforman el corpus de este trabajo fueron seleccionados a partir de los resultados recibidos mediante las alertas del buscador Google (Google Alerts) con una frecuencia diaria durante todo 2016. Dicha herramienta fue seleccionada como fuente primaria debido a que, además de poseer un buscador amigable al usuario y de uso gratuito, permite acceder a publicaciones de información general de todas las provincias argentinas y cuenta con, al menos, una actualización por día.

Dichas alertas fueron creadas bajo el concepto clave de «cocaína», dentro del sitio web del diario Clarín y restringido al territorio de la República Argentina. Al respecto, se vuelve necesario detallar las siguientes salvedades:

- Se tuvieron en cuenta las informaciones que consignaron la palabra «cocaína» en cualquiera de sus partes (tanto en el titular como en el cuerpo de la noticia).

- La palabra clave debió ser utilizada obligatoriamente en el contexto de la oferta de estupefacientes.

- Se estudiaron las informaciones publicadas en cualquiera de las secciones del medio; excepto las correspondientes a la sección de opinión. 
- Cada una de las notas se tomó como una unidad de análisis y fue contabilizada una única vez.

- No se consideró la cantidad de lectores/as obtenida por cada nota y, por esta misma razón, las cuestiones vinculadas a la posible «interactividad» no fueron analizadas.

Obtenido el resultado que arrojó el clipping, se procedió a adoptar una estrategia cuantitativa, es decir, una estrategia que se caracteriza por utilizar «la recolección de datos para probar hipótesis, con base en la medición numérica y el análisis estadístico, para establecer patrones de comportamiento y probar teorías» (Hernández Sampieri, Fernández Collado \& Baptista Lucio, 2006, pp. 5-8).

Para sistematizar los resultados, se construyó una matriz de datos estadísticos que permitió abstraer aspectos teóricamente relevantes de la realidad para analizarlos en busca de regularidades y de discontinuidades en función del objeto de estudio. Para tal fin, se tuvieron en cuenta otras tesis de posgrado (Orsini, 2015; Norzagaray, 2010) y trabajos científicos (Lancaster y otros, 2010) que abordan la situación del narcotráfico en diferentes países; en algunos casos, incluso, vinculada con los medios de comunicación. ${ }^{10}$

Teniendo en cuenta las referencias metodológicas de los trabajos mencionados se realizó una primera lectura o aproximación al corpus de publicaciones obtenido. Para llevar a cabo este proceso, fue necesario asociarse al club «Clarín 365» y pagar la correspondiente cuota mensual, a fin de sortear el escollo de tener una cantidad limitada de accesos por día y de poder acceder a cada una de las publicaciones las veces que fuera necesario y por el tiempo que se considerara pertinente."

Desde el inicio del procesamiento de los datos, se observaron ciertas repeticiones de temas que convergían con el objeto de estudio, la cuales fueron colocadas en una lista. Si bien en el presente texto solo se desarrollan las tres primeras categorías, es importante consignar todas las que surgieron: tipo de información, criterio de noticiabilidad, fuente, ubicación del hecho, cantidad de estupefaciente, otros elementos decomisados, etapa de producción / fabricación en la que la cocaína es mencionada y etapa de la ruta en la que la cocaína es mencionada.

Después de construidas dichas categorías, se las tradujo a una tabla en la que se incluyeron datos salientes para la identificación de cada unidad de análisis como número de orden o codificación y link correspondiente. Dicha tabla o ficha [Ver Anexo] fue aplicada a todas las publicaciones obtenidas, a partir de considerar a cada noticia como 
una unidad de análisis, y cada variable se tradujo en una columna. De esta forma, a las noticias se les atribuyó un valor (y solo uno) en cada variable relevante (Ariza \& Beccaria, 2019).

Luego de someter todas las publicaciones a la tabla de referencia, los resultados de las diferentes variables fueron sumados a través de listas que permitieron calcular sus respectivos porcentajes. A partir de ellos, se elaboraron los correspondientes gráficos de barra y se redactaron las observaciones que se exponen a continuación, a fin de desbrozar el imaginario social que, en términos de Baczko (1999), proyectó el diario digital Clarín acerca de la situación de la Argentina con respecto al tráfico ilícito de clorhidrato de cocaína durante 2016.

\section{El imaginario social sobre el narcotráfico en la sección policiales de Clarín}

En 2016, la versión digital del diario Clarín se organizaba en doce secciones diferentes: Política, Economía, Sociedad, Mundo, Cultura, Opinión, Ciudades, Policiales, Deportes, Espectáculos, Humor e Ilustraciones y Clasificados. Pese a esta vastedad de opciones, todas las novedades presentadas al lectorado en relación con la oferta de estupefacientes se ubicaron en la sección «policiales», respondiendo al mismo modelo de creación lingüística.

Por este motivo, lo más importante de señalar es que el hecho de que la totalidad de las notas hayan sido publicadas en esa única sección implica que no se vean reflejadas las diferentes aristas que propone la definición del PMD, específicamente en cuanto a la oferta de estupefacientes. Es decir, el medio decidió presentar a su lectorado una posición en la cual se considera que la persona que comete un delito debe ser abordada solo por policías y por fuerzas de seguridad, reduciendo la situación a una cuestión que compete únicamente al ámbito de la seguridad y que se encuentra enmarcada en la visión anacrónica de la «guerra contra las drogas».

Por esto, se entiende que el diario digital Clarín soslayó en sus publicaciones el objeto mismo del PMD, que intenta centrarse en las personas, abordándolas de forma integral, multidisciplinaria, haciendo foco en la calidad de la salud, el respeto de los derechos humanos, la consideración de las disparidades de género y la atención de los grupos vulnerables. 
Una vez constatado el hecho de que todas las notas estaban redactadas con características propias del género policial, se buscó dilucidar, en el universo conformado por las 87 publicaciones, cuáles fueron los hechos considerados noticiables. Estos resultaron ser cuatro: 1) procedimientos-allanamientos, 2) seguimiento de causas, 3) estudios técnicos y 4) casos aislados. La cantidad de repeticiones puede observarse a continuación:

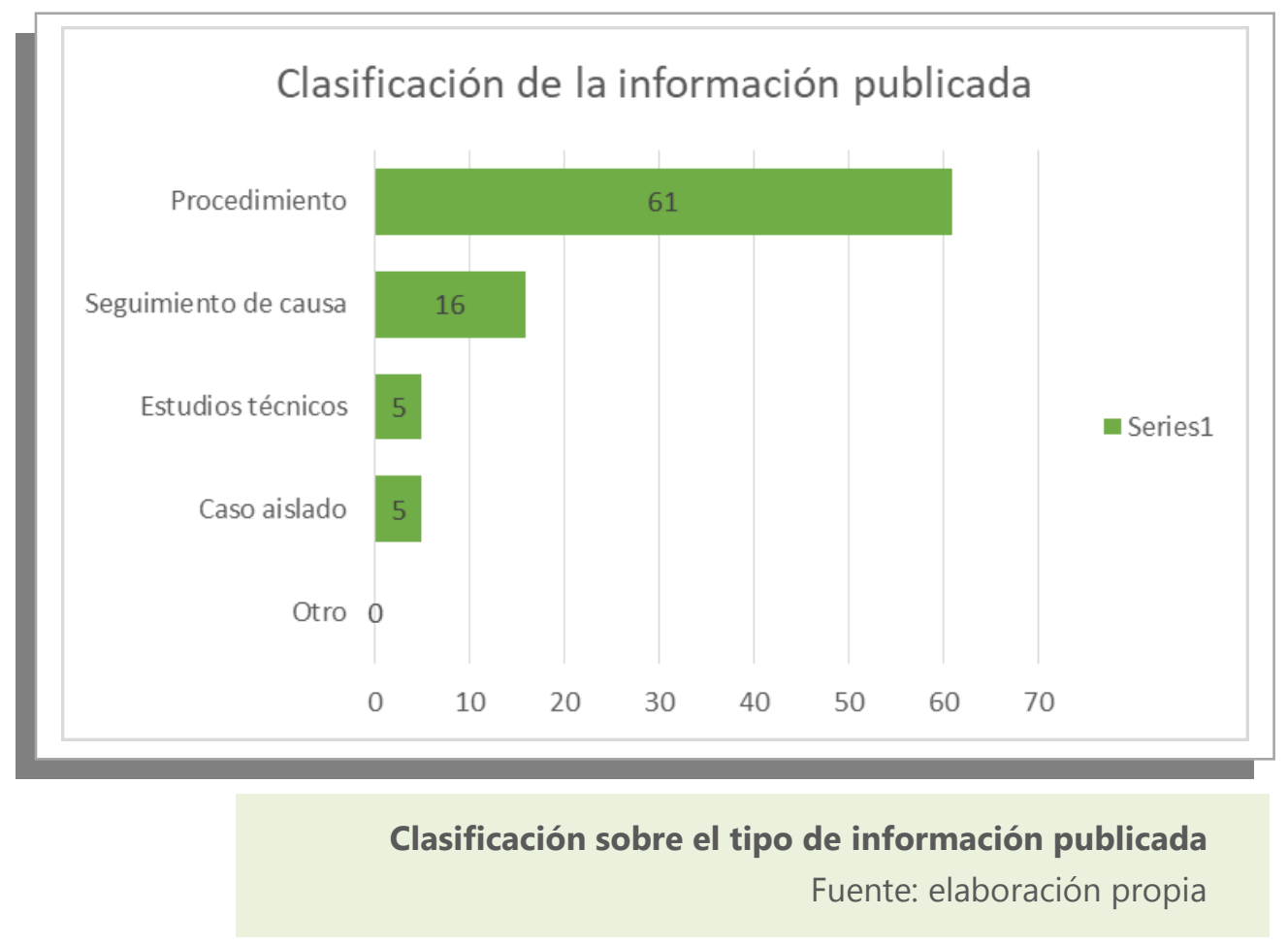

\section{Procedimientos-allanamientos}

Los hechos relacionados con procedimientos, allanamientos o demás acciones llevadas a cabo por cuerpos provinciales de seguridad o por Fuerzas Federales representan 70,1\% de las publicaciones relevadas. De esto se desprende que durante 2016 el interés del diario se orientó a construir un imaginario centrado en la preponderancia casi absoluta de la policía en dirección a intentar impedir el tráfico ilegal de estupefacientes en desmedro de cualquier otro actor social. Asimismo, en todas las notas se aprovechó a remarcar que las instituciones vinculadas a la seguridad deben trabajar de forma mancomunada sin distinción de jurisdicciones.

Vale señalar que si bien las Fuerzas Federales se dividen en Policía de Seguridad Aeroportuaria (PSA), Gendarmería Nacional Argentina (GNA), Policía Federal Argentina (PFA) y Prefectura Naval Argentina (PNA), el diario no establece diferencias en su 
accionar y cataloga sus conductas como «hechos policiales». Todo ello, implica deducir que la fuerza simbólica de «la policía» está omnipresente en la construcción discursiva de la noticia.

Solo por nombrar algunos ejemplos, la nota «No pasó de Formosa. Un viaje de 3.000 kilómetros con droga en latas de durazno»(Clarín, 11/02/2016), refiere del siguiente modo a las detenciones realizadas por la Gendarmería Nacional:

Un hombre fue detenido en Formosa por transportar en un micro de larga distancia casi 10 kilos de marihuana y 3,5 gramos de cocaína acondicionados entre su equipaje y en latas de durazno en conserva. El arresto tuvo lugar el martes pasado tras un control policial realizado por Gendarmería en un micro procedente de Clorinda, en la frontera con Paraguay, con destino a Río Gallegos, Santa Cruz (Clarín, 11/o2/2016).

Otro claro ejemplo en el que se generaliza cualquier control como policial es el que presenta la nota «Operativos en Hurlingham. Secuestran armas, cocaína y marihuana en 10 allanamientos simultáneos» (Clarín, 02/07/2016). En el texto se explicita que los allanamientos fueron efectuados por la Gendarmería, divisándose perfectamente sus uniformes en la foto que acompaña al texto, pero aun así la noticia queda enmarcada en un hecho policial, aunque esa Fuerza no haya intervenido.

De manera paralela a la forma en la que el medio instala a las acciones de las fuerzas de seguridad como clave para reducir este delito, se detecta que nunca informó sobre resultados negativos de peritajes, de allanamientos o de otras actividades. En ese marco, propuso un imaginario en cual el accionar de las Fuerzas Federales y de las policías provinciales se presenta como infalible e indiscutible, otorgándole el principio de autoridad, en línea con las directivas del gobierno de CAMBIEMOS que, a través de ellas, se mostró poco indulgente con los vendedores de estupefacientes.

\section{Seguimiento de causas}

$\mathrm{Al}$ desagregar la muestra, se observa que $18,3 \%$ de las notas corresponde a seguimientos de causas que no necesariamente se iniciaron o concluyeron en el lapso de estudio y que, al no obtener -en la mayoría de las oportunidades- sus fallos rápidamente, les permiten a sus redactores aplicar el recurso de la «espectacularización» (FLACSO, 2016) de los 
hechos y presentar la información como un relato de tipo ficcional, justamente, con elementos espectaculares y con detalles sobre los involucrados o sobre los sucesos que son dignos de comparar con historias propias de la cinematografía o la literatura.

Las cuestiones relativas a la espectacularización contribuyen a crear sobre las causas un imaginario impreciso, porque en el afán de sumar centimetraje «informativo» se reducen los criterios de rigurosidad periodística. Así, en varias oportunidades, se traen a colación hechos de dudosa vinculación con la investigación -como cuestiones personales de los/as acusados/as- que, además de impedir una contextualización de la situación, dejan espacios vacíos que son completados según la imaginación de cada lector/a. De este modo, quienes no tienen cercanía con categorías sólidas sobre el narcotráfico no siempre llegan a conclusiones asertivas.

En la construcción de este imaginario, el Poder Judicial como actor político ocupa el segundo lugar en la jerarquización aplicada por Clarín. Un claro ejemplo es la nota «Cayó en Belgrano: "Rodrigo", el narco mexicano que amaba las Harley-Davidson» (Clarín, 30/04/2016), donde se actualiza información sobre el mexicano Rodrigo Pozas Iturbe, quien en 2008 fue catalogado como uno de los jefes de un cartel mexicano que estaba desplegado también en la Argentina y que tenía estrecha vinculación con la «ruta de la efedrina». ${ }^{12}$

El análisis de la nota muestra que el titular hace hincapié en el gusto del detenido por ese tipo de vehículos, sin mencionar que se trata de una de las personas sospechadas de ser uno de los principales narcotraficantes que habitan en el país. La bajada tampoco se centra en el perfil o en el historial del personaje principal de la nota, sino que resalta su modus operandi y utiliza frases ramplonas como «se había metido», para generar cierta empatía con el prodestinatario: «Viajaba con su moto a Santa Fe a buscar cocaína para entregársela en Buenos Aires a "mulas" que la llevaban a Europa escondida en zapatillas. También se había metido en el tráfico de pastillas hacia la Argentina».

Es extraño que a partir del uso de la metáfora, y luego de señalar repetidas veces el fanatismo del mexicano por las Harley Davidson, recién se mencione el nombre completo de un involucrado que tantas veces estuvo en sus páginas, lo que es posible corroborar gracias a los dos hipervínculos que se promocionan para ser leídos entre los párrafos de la nota. «El hombre de la moto resultó ser Rodrigo Pozas Iturbe, 43 años, mexicano, dueño de un prontuario curioso: en 2008 fue detenido acusado de ser uno de 
los líderes narco detrás de la llamada "ruta de la efedrina" y de tener contactos con las víctimas del triple crimen de General Rodríguez».

Asimismo, el párrafo precedente se vuelve sumamente importante para Clarín a la hora de intentar revivir en el lectorado la vinculación de causas muy renombradas, como el descubrimiento del laboratorio de Maschwitz, el tráfico ilegal de efedrina a México, los crímenes de Damián Ferrón, Sebastián Forza y Leopoldo Bina, ${ }^{13}$ la «mafia de los medicamentos»y, sobre todo, los supuestos aportes de grupos de narcotraficantes a la primera campaña electoral de Fernández de Kirchner, mostrándose, en este caso, como un actor político contrario a la figura de la ex presidenta.

Tampoco es menor que se intente hacer referencia a la importancia de que el país cuente con legislación que contemple nuevas figuras penales, lo que se materializará recién en octubre de 2016 -meses más tarde de esta publicación- mediante la Ley 27304, a partir de la cual se otorgan beneficios al imputado arrepentido por la colaboración prestada. Para ello, el diario digital Clarín presenta una secuencia en la que tampoco escatima el empleo del recurso de la espectacularización para referir a la supuesta operatividad de la Justicia: el arrepentido confiesa, rápidamente la Fiscal pide su detención, aún con mayor velocidad el Juez libra la orden, casi al instante la policía lo detiene y, con una capacidad de lectocomprensión envidiable para cualquier humano, el abogado lee 4.60o páginas a la velocidad de la luz

En cuanto a Pozas Iturbe ${ }^{14}$ su situación legal terminó de complicarse la semana pasada, cuando uno de los involucrados en la causa de Aguinsky declaró como «arrepentido» y lo vinculó con el contrabando de cocaína hacia Europa y también con el tráfico de drogas sintéticas desde Europa a Argentina. [...] Con el testimonio del «arrepentido», el jueves 21 de abril, la fiscal Ruiz Morales le pidió al juez Aguinsky la detención de Pozas Iturbe y el allanamiento de su departamento de Belgrano. Pocas horas después, el mexicano ya estaba siendo indagado. Luego de que su abogado leyera hoja por hoja los 23 cuerpos del expediente (unas 4.600 páginas) [Clarín, 30/04/2016].

\section{Estudios técnicos}

Las publicaciones que hicieron referencia a diferentes presentaciones de estudios técnicos o a foros de discusión de políticas públicas en las que participaron autoridades gubernamentales de alto rango ocuparon tan solo 5,74\% del total de la muestra. 
Un ejemplo de ello quedó consignado en la nota «Prevención e investigación, los ejes para combatir la droga» (Clarín, 04/11/2016), en cuya bajada se menciona: «Expertos locales y autoridades gubernamentales analizaron las medidas adoptadas y los aspectos pendientes en el marco del “Tercer Simposio ¿Cómo prevenir el narcotráfico?” del Observatorio de Prevención del Narcotráfico (OPRENAR)». Con respecto al OPRENAR, cabe señalar que el Secretario de Seguridad de la entonces ministra de Seguridad Patricia Bullrich, Eugenio Burzaco, estuvo muy involucrado con dicha institución antes de ingresar al gobierno nacional, tal como puede observarse en el libro Propuestas de Políticas Públicas Integrales para la Prevención del Narcotráfico (OPRENAR, 2015).

En tanto, que no aparezcan a lo largo de toda la muestra voces diferentes a las gubernamentales, demuestra que al diario objeto de estudio no le interesó mostrar a su lectorado ningún tipo de referencia científica ni suministrar información sobre actualizaciones técnicas en la materia. En virtud del análisis, se entiende que Clarín promovió un imaginario social en el que los estudios científicos con autoría de funcionarios/as o de allegados/as a CAMBIEMOS son aquellos válidos, mientras que los pertenecientes a voces disidentes no tienen asidero; es decir, si bien podrían contar con la misma rigurosidad científica, no los reconoció como actores políticos. Así, la estrategia del gobierno, en la que el narcotráfico es uno de sus principales problemas a resolver, continuaba siendo avalada por el diario.

\section{Casos aislados}

Igual porcentaje que la categoría anterior (5,74\%) obtuvieron los casos considerados aislados por la particularidad de lo que representaron, como el asesinato con extrema violencia de una vendedora al menudeo mientras realizaba su trabajo en la ciudad de Rosario: «Con sello mafioso. Otra muerte narco en Rosario: asesinaron a balazos a una joven que vendía droga en la calle» (Clarín, o8/10/2016).

A partir de los porcentajes obtenidos y de la sumatoria de las categorías «procedimientos» (70,1\%), «seguimientos de causas» $(18,3 \%)$ y «presentación de informes gubernamentales» $(5,74 \%)$, resalta que 92,2\% de las publicaciones del periódico digital fueron producto del trabajo realizado por alguno de los tres poderes del Estado. De todos modos, no deja de ser totalmente descollante el lugar que se le otorga al trabajo realizado por las fuerzas de seguridad. 
De lo anterior, se entiende que durante 2016 la versión digital del diario Clarín apeló a crear un imaginario social tendiente a demostrar a sus prodestinatarios operatividad y proactividad por parte del Estado en materia de reducción de la oferta de estupefacientes. En su carácter de actor político, le adjudicó a los/as funcionarios/as gubernamentales el principio de autoridad, reforzando la idea de que el uso de la fuerza, «la mano dura» y el despliegue de más recursos policiales por parte del Estado es la solución al narcotráfico, en detrimento de la superación del paradigma de la «guerra contra las drogas» por el enfoque del «Problema Mundial de las Drogas».

\section{Fuentes consultadas}

Una vez que se conoció la forma empleada por el medio de comunicación para clasificar la información analizada, se profundizó en las voces que habían contribuido al contenido de la nota.

\section{Funcionarios públicos}

En estrecha relación con el apartado anterior, las voces de los/as funcionarios/as públicos/as $(52,87 \%)$ fueron las más requeridas a la hora de construir las noticias. El estudio pormenorizado de las 87 notas que conforman la muestra permitió apreciar que en varios casos se preservó la identidad del funcionario y solo se hizo referencia a la dependencia gubernamental de pertenencia, lo que contribuye a confirmar la percepción de que Clarín fomentó la creación de un imaginario social que respaldó la política de CAMBIEMOS en materia de restricción de la oferta de estupefacientes, al tiempo que preservó la identidad de aquellos que se dedican a tareas vinculadas al narcotráfico por cuestiones de seguridad.

Ejemplo de ello es la declaración que se ofrece en la nota "Cinco detenidos: Cae una banda que traficaba armas y drogas desde la villa 1-11-14: tenían un arsenal» (Clarín, 02/10/2016), en la que menciona: «Desde el Ministerio (de Seguridad de la Nación) explicaron que esta organización "se proveía de las armas mediante la connivencia con un armero e instructor de tiro, quien, a su vez, tenía conexión con un acopiador ilegal de armamento de guerra"». 


\section{Fuerzas de seguridad}

Respecto de la instalación en la sociedad de un imaginario en el que la voz de los funcionarios públicos es inapelable, Clarín aceptó la versión policial de los hechos en $42,52 \%$ de la muestra. En términos periodísticos, esto significa que otorgó a las fuerzas de seguridad el «principio de autoridad», al legitimar sus declaraciones y atribuirle valor a sus narraciones, tal como sucede, por ejemplo, con la declaración del Comandante de Gendarmería Nacional, Luis María Cané, quien indicó: «Estos son los resultados de los controles que hacemos en los diferentes caminos de la provincia y son números importantes», según consta en la nota «Tucumán: Encuentran 55 kilos de cocaína escondidos en bolsas de ajíes» (Clarín, 15/11/2016).

En la nota «Cada vez más droga: el secuestro de éxtasis creció un 600 por ciento respecto a 2015» (Clarín, 15/12/2016), también se pone de manifiesto que el valor de las palabras de las fuerzas de seguridad no es cuestionado en ningún momento ni las afirmaciones contrastadas de alguna forma, tal como se lee en la bajada de dicha nota: «Las fuerzas federales ya incautaron 144.997 pastillas, frente a las 19.763 de igual período del año pasado. La Aduana, en tanto, cuadriplicó sus incautaciones. Muchas llegan en encomienda. No fue una excepción sino una tendencia». En este caso, es llamativo que se aluda a tendencias, dado que no se mencionan los valores de períodos anteriores, necesarios metodológicamente para establecer una tendencia.

De este modo, el diario reafirmó durante 2016 un imaginario en el cual las fuerzas de seguridad combatían con eficacia al narcotráfico en la Argentina, e indirectamente destacaba los decomisos del gobierno de Macri al contrastarlos con las cifras del último año de Fernández de Kirchner, lo cual reafirma, nuevamente, su posición como actor político.

\section{Especialistas, detenidos o víctimas}

De forma similar a lo que sucede con las expresiones de las fuerzas de seguridad, las voces de los detenidos o de las víctimas de hechos delictivos vinculados al narcotráfico no se ven expresadas en ninguna de las informaciones relevadas, lo que convierte a estas personas en «antidestinatarios» (Verón, 2005).

En este mismo sentido, fueron nulas las referencias a papers o a especialistas ajenos al Estado, por lo que se entiende que la comunidad científica, las ONG y la sociedad civil no 
fueron consideradas por el medio en tanto actores legitimados, por no contribuir a la creación del imaginario social buscado y que, a los fines de esta investigación, refuerza el hecho de que el diario Clarín fue aquiescente con el gobierno de Mauricio Macri en términos de restricción del narcotráfico.

Por lo mencionado, se infiere que el medio no solo no fue independiente del discurso oficial en la materia -la sumatoria de las categorías «funcionario» y «fuerzas de seguridad» arroja un total de $95,39 \%$ con respecto al total-, sino que en varias oportunidades soslayó de forma expresa las versiones de los hechos de ciudadanos corrientes, desconociéndolos como actores.

\section{Prófugos}

A diferencia de la marcada participación de los/as funcionarios/as de CAMBIEMOS en la construcción de las noticias que conforman el corpus analizado, otros/as ciudadanos/as implicados/as solo están presentes en 1,14\% del total de la muestra. Cabe señalar, además, que este último porcentaje estuvo representado por personas vinculadas con el Frente para la Victoria (FPV), el partido político de los ex presidentes Néstor Kirchner y Cristina Fernández de Kirchner.

Por tal razón, a partir de este punto de la investigación se pudo comenzar a observar la forma en la que el diario Clarín planteó una suerte de dicotomía a partir de la cual mientras los miembros de CAMBIEMOS eran presentados como honestos y proactivos, aquellos que defendían las ideas del FPV eran señalados como corruptos y como cercanos a actividades ilícitas. Como ejemplo, puede señalarse la ocasión en la que el medio reprodujo una noticia de un diario de Pocitos, Salta. «Desde la clandestinidad, el concejal acusado de narco dice que "es una cama” (Clarín, 25/12/2016), en la que se cita:

«Es una cama. Te juro que no tengo nada que ver. Me la hicieron re bien, pero lo voy a aclarar». Así empieza el breve descargo ante la prensa que hizo el concejal salteño que tiene pedido de captura internacional en una causa narco por medio del chat de Facebook (Clarín, 25/12/2016).

De esta forma, el medio afirmaba haberse comunicado con un concejal prófugo de la justicia por haber promovido que ciertos medios de transportes fueran eximidos de controles vehiculares de rutina para facilitar el ingreso de cocaína al país. 
Vale resaltar que la nota analizada está dirigida a los prodestinatarios del diario, al reforzar el imaginario social según el cual los políticos pertenecientes al FPV son conniventes con el narcotráfico, sin siquiera sugerir el casi nulo grado de injerencia que un concejal de un pequeño municipio del interior podría tener en las divisiones antidrogas de las Fuerzas Federales desplegadas a lo largo y ancho del país.

Este caso puede señalarse, además, como uno de los que más ha utilizado el recurso de la multimedialidad propia del ciberperiodismo, dado que presenta conversaciones privadas de la red social Facebook entre el prófugo y el periodista, así como publicaciones en su muro, realizadas durante su campaña electoral, en las que hacía referencia a su honestidad, elementos que son dejados al alcance del prodestinatario para continuar contribuyendo al imaginario social que presentaba a los políticos cercanos al FPV como conniventes con el narcotráfico.

\section{Familiares de detenidos}

Respecto del total de la muestra, otro 1,14\% corresponde a informaciones cuya principal fuente está dada por familiares de detenidos. Esta última cuestión se observa en una noticia de lo más curiosa: «Llegó de España engañado por traficantes: La trágica historia de la "mula" que murió sin saber lo que hacía» (Clarín, 11/o4/2016). Según la nota, el padre del detenido -David Ríos, de 19 años- se encontraba haciendo reclamos ante la Justicia argentina dado que su hijo habría sido captado en Aragón, España, por las redes delictivas en clara situación de abuso por su discapacidad. Al llegar al país, como mula de 2,8 k de cocaína, fue detenido. Tiempo después, el pabellón de la Unidad 20 del Servicio Penitenciario Federal (SPF) sufrió un incendio y el joven falleció en el acto. ${ }^{15}$

La reproducción de este tipo de información, nutrida vastamente por el recurso de la espectacularización -la nota comienza con la frase: «El 31 de mayo de 2011, Roser Ríos se despertó de madrugada en su casa de Aragón, España, cuando sonó su celular», en la que se recalca uno de los años en los que gobernó el kirchnerismo-, permite colegir que el periódico intentaba plantear un imaginario social en el cual el Estado en ese período había sido ineficiente en la materia, que las instalaciones del SPF eran sumamente precarias y que la Justicia era aún menos operativa. Dicha táctica es reforzada al momento de citar al padrastro de la víctima: 
«En el fondo, el menor problema de todo lo que pasó es la droga que le encontraron», dice Manuel Luque, marido de Roser, la mamá de David, desde España. «Si hubiera ley de discapacitados, David estaría con nosotros y no habría muerto por negligencias de terceros». Desde ese día, se enteró de más casos de españoles discapacitados y sin empleo engañados por narcos (Clarín, 11/04/2016).

\section{Investigaciones impulsadas por periodistas}

En el período analizado, las investigaciones sobre la materia impulsadas por el propio medio de comunicación también fueron escasas $(2,29 \%)$ e hicieron siempre referencia a sucesos ocurridos con ex funcionarios/as del gobierno pertenecientes al FPV, es decir, opositores al gobierno de CAMBIEMOS. Esta decisión permite entender que Clarín también utilizó una estrategia informativa que buscaba instalar en sus prodestinatarios un imaginario social basado en la dicotomía «funcionarios del FPV corruptos / allegados a CAMBIEMOS operativos y exentos de vinculaciones espurias», refirmando su postura como actor político favorable al gobierno de Macri.

De esta forma, y como ocurre en «Denuncia: PPT reveló más conexiones entre Aníbal Fernández y tres casos de narcotráfico» (Clarín, 10/07/2016), en las notas pueden hallarse declaraciones del siguiente tipo:

\footnotetext{
Más conexiones entre Aníbal Fernández y el tráfico de drogas. Periodismo Para Todos mostró que existe una vinculación, de acuerdo a los expedientes judiciales, entre el ex funcionario kirchnerista y el doble crimen de Unicenter, el triple crimen de General Rodríguez y el tráfico de una tonelada de cocaína a España realizado por los hermanos Juliá (Clarín, 10/07/2016).
}

En la edición digital, Clarín adoptó como principio de autoridad uno de los programas de mayor rating en el canal de señal abierta y con el cual comparten grupo económico. Para el hecho, la construcción es irrebatible, ya que tal como dice la frase popular hay que «ver para creer», y el diario actúa en consecuencia para darle solidez a su estrategia noticiosa, basada en «expedientes judiciales» que «Periodismo Para Todos mostró».

En el caso particular de la nota citada, llama la atención que Clarín no haya utilizado ninguno de los recursos a su disposición, como el de la hipertextualidad, para brindar a sus lectores/as mayores precisiones sobre los crímenes mencionados o sobre el mismo 
Aníbal Fernández. Aún más extraño es que solo empleara el recurso de la multimedialidad para presentar al conductor del programa, Jorge Lanata, sentado en el set televisivo, cuando se podría haber puesto un fragmento del video sobre el informe o haber mostrado el contenido de los expedientes judiciales, que si bien parecen ser clave en la presentación nunca son exhibidos. ${ }^{16}$

Así como antes «mostró», ahora el programa «revela», muestra lo que está oculto:

PPT reveló que el fiscal Ramírez, que tenía el celular que antes había sido de Novo, recibe un llamado y escucha que una mujer se presenta como la «secretaria de Aníbal Fernández» y le anuncia que «el jury va a salir bien», en referencia al jury de enjuiciamiento que se le seguía a Novo, hecho que finalmente sucedió (Clarín, 10/o7/2016).

Frente estas afirmaciones, se podría plantear la duda sobre cómo es posible que un fiscal pueda acceder al celular de otro fiscal.

Respecto de Novo, en párrafos anteriores, el medio había expresado como agravante «a quien el informe muestra en un acto de Aníbal Fernández», y respecto del Jury de enjuiciamiento, que la secretaria de Fernández le «anticipa» que va a salir bien, tal como ocurrió. Así, las piezas del rompecabezas encajan perfectamente, pero jamás se hace referencia a que en el Consejo de la Magistratura el FPV no tenía mayoría y que al organismo había ingresado el diputado Pablo Tonelli -representante del oficialismo CAMBIEMOS- para ocupar una banca que, en realidad, le correspondía al FPV.

\section{Voces independientes}

Al finalizar el relevamiento, se corroboró que Clarín en ningún momento consultó fuentes tales como voceros de universidades, especialistas en la materia o estudios técnicos independientes, desdeñando cualquier tipo de avance científico u opiniones con sustento que pudieran contribuir a comprender el fenómeno de forma neutral y objetiva. Es decir, creó un imaginario social en el que se eludió de manera significativa el rol de las ONG y de las organizaciones de la sociedad civil (OSC) como fuentes de autoridad en la temática examinada, desconociéndolos como actores políticos con legitimidad para intervenir en la materia. 
En líneas generales, luego del análisis de las fuentes que fueron consultadas para construir las noticias, se evidencia que el diario de referencia no contrastó las versiones oficiales de los hechos ni indagó sobre ellos desde otro punto de vista; incluso, soslayó el rico debate académico existente en la sociedad y en la comunidad científica como el producido por el International Drug Policy Consortium (IDPC) o el Grupo Pompidou, entre tantas organizaciones y asociaciones. Por esto, se entiende que durante 2016 el multimedio fue condescendiente con el gobierno de Macri y evitó todo tipo de crítica a su gestión en materia de tráfico ilegal de clorhidrato de cocaína.

\section{Palabras finales}

Si bien este trabajo se encuentra enmarcado en un proyecto elaboración mucho más ambicioso, se entiende que el diario Clarín como actor político, en su versión digital del año 2016, cubrió al narcotráfico dirigiéndose casi con exclusividad a un prodestinatario en el cual buscó instalar un imaginario social basado en una dicotomía en la que, por un lado, los/as funcionarios/as kirchneristas ${ }^{17}$-en ejercicio durante el 2016 o pertenecientes a la gestión anterior- tuvieron algún vínculo con miembros de redes de narcotraficantes o fueron conniventes con el tráfico ilícito de cocaína, mientras que los representantes de la gestión CAMBIEMOS aparecen como honestos, capaces de poner límites a este delito, y aptos para velar por la seguridad de los ciudadanos y de desarticular a grandes bandas.

Para llevar a cabo la creación de dicho imaginario social, el diario medio se valió de recursos tradicionales a la hora de construir «las noticias narco», tales como:

- La narratividad: a través del relato de historias sin contextualización pero con un gran uso de la espectacularización.

- El principio de autoridad: al darle voz solo a los/as funcionarios/as que en ese momento se encontraban en funciones y a las fuerzas de seguridad en detrimento de cualquier voz opositora.

- El principio de ironía: al incluir únicamente fuentes kirchneristas cuando un ilícito grave tenía lugar en distritos por ellos gobernados y por el hecho de dirigirse prácticamente con exclusividad $^{18}$ a un público prodestinatario.

- Otros propios del ciberperiodismo: como el uso del hipertexto y la multimedialidad (fotos y videos proporcionados por otras empresas del Grupo, como TN o Canal 13). 
Vale señalar que ese imaginario social fue sumamente difuso respecto de todas las dimensiones teóricas explicitadas sobre narcotráfico en el país, excepto por la óptica punitivista que el medio avaló en todas las publicaciones y que hasta podría haber fomentado el imaginario de vivir en una sociedad ingobernable por su grado de inseguridad, frente a lo cual la única solución capaz de revertir tal situación es reforzar políticas de «mano dura» y reforzar el accionar de las fuerzas de seguridad.

Para justificar una mayor presencia de las Fuerzas Federales en tareas de narcotráfico, el diario recurrió a diferentes estrategias: se basó en declaraciones que presentaron a la Argentina como «un mercado perfecto para las drogas», ${ }^{19}$ difundió la cantidad de detenciones de narcotraficantes con solicitud de captura internacional buscados desde hace años, comparó valores de incautaciones de estupefacientes entre las dos gestiones de diferente signo político y mostró todos los elementos decomisados como peligrosos para una vida en comunidad. Es decir, todas situaciones que se alejan del paradigma del PMD, que entiende que abocarse solo a la oferta deja a las acciones de prevención y de asistencia sin relevancia alguna, y pierde a la persona como eje de toda política pública.

Por ello, adquiere singular sentido mencionar que si bien no se constató que a partir de la derogación del Decreto 267/15 (por el cual el multimedio accedió a la posibilidad de brindar el servicio de cuádruple play) se haya evitado que la publicación de cualquier crítica al gobierno de CAMBIEMOS sea divulgada por el multimedio, sí se puede afirmar que las publicaciones objeto de estudio fueron redactadas de forma sesgada y ofrecieron una construcción de la información sobre este delito de una forma más cercana al paradigma de «guerra contra las drogas», en soslayo de los cambios sociales y del avance en materia de lucha de derechos que en los últimos años venían ocurriendo en el país.

A modo de cierre, se espera que este artículo constituya un aporte para repensar las formas en las que el diario Clarín comunicó la restricción de la oferta de estupefacientes, en general, y de cocaína, en particular, y para reflexionar sobre las características que presenta el género policial que es utilizado en los medios de comunicación. 
Anexo

\begin{tabular}{|c|c|c|c|c|c|c|}
\hline Número de nota & $\begin{array}{c}\text { Sección } \\
\text { Firma } \\
\text { de periodista } \\
\end{array}$ & Link & & & & \\
\hline Tipo & Procedimiento & $\begin{array}{l}\text { Seguimiento } \\
\text { de causa }\end{array}$ & Oficial & Caso aislado & Otro & \\
\hline $\begin{array}{c}\text { Criterio } \\
\text { de noticiabilidad }\end{array}$ & Violencia & Extravagancia & $\begin{array}{l}\text { Dinámica } \\
\text { del PMD }\end{array}$ & $\begin{array}{c}\text { Información } \\
\text { oficial }\end{array}$ & $\begin{array}{c}\text { Valor } \\
\text { incautación }\end{array}$ & Otro \\
\hline Fuente & Funcionarios & $\begin{array}{l}\text { Fuerzas de } \\
\text { Seguridad }\end{array}$ & $\begin{array}{l}\text { Víctima } \\
\text { del hecho }\end{array}$ & Detenido & $\begin{array}{l}\text { Cercano } \\
\text { al hecho }\end{array}$ & Otro \\
\hline \multicolumn{7}{|l|}{$\begin{array}{l}\text { Ubicación } \\
\text { del hecho }\end{array}$} \\
\hline \multicolumn{7}{|l|}{$\begin{array}{c}\text { Cantidad } \\
\text { de estupefaciente }\end{array}$} \\
\hline \multicolumn{7}{|l|}{$\begin{array}{l}\text { Otros elementos } \\
\text { decomisados }\end{array}$} \\
\hline \multicolumn{2}{|c|}{$\begin{array}{c}\text { Etapa de producción/fabricación } \\
\text { en la que la cocaína } \\
\text { es mencionada }\end{array}$} & \multicolumn{5}{|c|}{$\begin{array}{l}\text { Etapa de la ruta en la que la cocaína } \\
\text { es mencionada }\end{array}$} \\
\hline Siembra/cultivo & & $\begin{array}{l}\text { Destino final } \\
\text { de consumo } \\
\text { personal }\end{array}$ & & & & \\
\hline Guarda de materia prima & & $\begin{array}{l}\text { Destino final } \\
\text { por venta local }\end{array}$ & & & & \\
\hline Cristalización & & $\begin{array}{l}\text { Tránsito } \\
\text { a destino final }\end{array}$ & & & & \\
\hline Estiramiento & & No menciona & & & & \\
\hline \multicolumn{2}{|l|}{ Fraccionamiento } & & & & & \\
\hline \multicolumn{2}{|l|}{ Comercialización } & & & & & \\
\hline \multicolumn{2}{|l|}{ Distribución } & & & & & \\
\hline \multicolumn{2}{|l|}{ Otorgamiento en pago } & & & & & \\
\hline \multicolumn{2}{|l|}{ Almacenamiento } & & & & & \\
\hline \multicolumn{2}{|l|}{ Transporte } & & & & & \\
\hline \multicolumn{2}{|l|}{ Tenencia personal } & & & & & \\
\hline No menciona & & & & & & \\
\hline
\end{tabular}

Tabla con las categorías de análisis aplicadas a las notas de la muestra Fuente: elaboración propia 


\section{Referencias}

Albornoz, L. A. (2005). Los diarios online de información general: el caso de los grandes periódicos en español (Tesis doctoral). Facultad de Ciencias de la Información, Universidad Complutense de Madrid. Madrid, España. Recuperado de http://webs.ucm.es/BUCM/tesis/inf/ucm-t2848o.pdf Ariza, L. y Beccaria, M. (2019). Víctimas y victimarios: niñez y adolescencia en las noticias televisivas. Comunicación, Política y Seguridad, 1(1), 63-87. Recuperado de https://publicaciones.sociales.uba.ar/index.php/revistacomunicacion/article/view/3554

Baczko, B. (1999). Los imaginarios sociales. Memorias y esperanzas colectivas. Ciudad Autónoma de Buenos Aires, Argentina: Nueva Visión.

Barrios Puga, A. (2013). El ciberperiodismo en México: realidades, desafíos y oportunidades (Tesis de doctorado). Facultad de Ciencias de la Comunicación, Universidad de Santiago de Compostela. Santiago de Compostela, España. Recuperado de https://minerva.usc.es/xmlui/bitstream/handle/10347/9558/rep_540.pdf?sequence=1 \&isAllowed $=\mathrm{y}$

Borrat, H. (1989). El periódico, actor político. Barcelona, España: Gustavo Gili.

Casermeiro de Peterson, A. (2003). Los medios en las elecciones: la agenda setting en la Ciudad de Buenos Aires. Ciudad Autónoma de Buenos Aires, Argentina: Educa. Recuperado de https://repositorio.uca.edu.ar/handle/123456789/7908

Collinao, F. y Cristante, J. (2015). De políticos de público conocimiento a público sin conocimientos de sus políticos. Trabajo presentado en el XII Congreso Nacional de Ciencia Política. Universidad Nacional de Cuyo (UNcuyo) / Sociedad y Argentina de Análisis Político (SAAP).

Collinao, F., Vázquez, J. y otros (2015). El narcotráfico analizado. Un recorrido por las principales características del tráfico ilícito de estupefacientes en Argentina según la literatura especializada. Trabajo presentado en el XII Congreso Nacional de Ciencia Política. Universidad Nacional de Cuyo (UNcuyo) / Sociedad Argentina de Análisis Político (SAAP). 
Decreto de Necesidad y Urgencia 267 (2015). Ente Nacional de Comunicaciones. Boletín Oficial de la República Argentina. Buenos Aires, 04/o1/2016. Recuperado de http://servicios.infoleg.gob.ar/infolegInternet/anexos/25500o-259999/257461/norma.htm

Defensa de la competencia autorizó la compra de Nextel por parte del Grupo Clarín (18 de abril de 2017). El Cronista. Recuperado de https://www.cronista.com/negocios/Defensa-de-la-Competencia-autorizo-compra-deNextel-por-parte-del-Grupo-Clarin-20170418-oo69.html

Díaz, C., Giménez, M. y Passaro, M. (2008). 19 de mayo de 1977: «De eso no se habla», Anuario de Investigaciones 2006 (pp. 61-69). La Plata, Argentina: Universidad Nacional de La Plata.

Donzelli, M. y Souto, M. (2011). Centros de procesamiento ilícito de estupefacientes en Argentina. Un análisis a partir de los casos judicializados. Ciudad Autónoma de Buenos Aires, Argentina: Dirección de Evaluación y Análisis Técnico del Tráfico Ilícito de Drogas-SEDRONAR. Recuperado de https://biblioteca.sedronar.gov.ar/cgibin/koha/opac-detail.pl?biblionumber=2365

Ducrot, O. (1989). El decir y lo dicho. Ciudad Autónoma de Buenos Aires, Argentina: Hachette.

Edo, C. (2003). Rasgos y normas de estilo ciberperiodístico. En J. Díaz Noci y R. Salaverría (Coords.), Manual de redacción ciberperiodística (pp. 353-383). Barcelona, España: Ariel. Escudero Chauvel, L. (1997). ¿Quién es el autor de las noticias? Acerca del contrato mediático de la información. Sociedad, (11). Recuperado de https://www.narrativas.com.ar/quien-autor-las-noticias-acerca-del-contrato-mediaticola-informacion-lucrecia-escudero/

Fernández de Kirchner, C. (2019). Sinceramente. Ciudad Autónoma de Buenos Aires, Argentina: Sudamericana.

Flacso Radio Ecuador (2016). Espectacularización. Recuperado de https://www.flacso.edu.ec/flacsoradio/programas/academicos/entre-lineas/308-entrelineas-19 
García, J. (2011). La Revista Social Tuenti. Análisis del modelo de comunicación y de la estrategia de marketing. Telos. Cuadernos de Comunicación e Innovación, (89), 139-145. Recuperado de

https://telos.fundaciontelefonica.com/archivo/numeroo89/analisis-del-modelo-decomunicacion-y-de-la-estrategia-de-marketing/?output=pdf

García Sigman, L. (2015). El lenguaje ciberperiodístico en las columnas de los cibermedios argentinos (Tesis de maestría). Departamento de Ciencias Sociales, Universidad de San Andrés. Ciudad Autónoma de Buenos Aires, Argentina.

Recuperado de http://repositorio.udesa.edu.ar/jspui/handle/109o8/10940

Grupo Clarín (1995). Declaración de propósitos. Recuperado de https://grupoclarin.com/institucional/declaracion-de-propositos

Hernández Sampieri, R., Fernández Collado, C. y Baptista Lucio, P. (2006). Metodología de la investigación. Ciudad de México, México: McGraw.

Isla, A. y San Martín, R. (2009). Representando las violencias y el delito.

El rol de los medios de comunicación. Cuadernos de Investigaciones Etnográficas,

(2), 3-28. Recuperado de

http://envios.unsam.edu.ar/escuelas/humanidades/centros/c_cie/pdf/cuadernos/I slaSanMartin.pdf

Knight Center for Journalism in the Americas and Open Society Foundations (2010). Coverage of drug traffking and organized crime in Latin America and the Caribbean. Recuperado de https://www.opensocietyfoundations.org/publications/coverage-drugtrafficking-and-organized-crime-latin-america-and-caribbean

Lancaster, K., Hughes, C., Spicer, B. y Matthew-Simmons, F. (2010). Illicit Drugs and the Media: Models of Media Effects for Use in Drug Policy Research. Drug and Alcohol Review, 30(4), 397-402. https://doi.org/10.1111/j.1465-3362.2010.00239.x Ley Nacional 26.522 (2009). Servicios de Comunicación Audiovisual. Boletín Oficial de la República Argentina. Buenos Aires, 10/10/2009. Recuperado de http://servicios.infoleg.gob.ar/infolegInternet/anexos/1550oo-159999/158649/norma.htm 
Martini, S. (2002). Agendas policiales de los medios en la Argentina: la exclusión como un hecho natural. En S. Gayol y G. Kessler (Comps.), Violencias, delitos y justicias en la Argentina (pp. 87-112). Ciudad Autónoma de Buenos Aires, Argentina: Manantial / Universidad Nacional de General Sarmiento.

Martini, S. (2007). La prensa gráfica argentina: reflexiones sobre la calidad periodística, la información «socialmente necesaria» y la participación ciudadana en las agendas sobre el delito. Recuperado de http://saboramilf.files.wordpress.com/2012/04/sintesisconsejodirectivo.pdf Masip, P., Díaz Noci, J., Domingo, D., Micó Sanz, J. L. y Salaverría, R. (2010). Investigación internacional sobre ciberperiodismo: hipertexto, interactividad, multimedia y convergencia. El Profesional de la Información, 19(6), 568-576. Recuperado de http://dadun.unav.edu/handle/10171/13561

Mauricio Macri: «Nuestras prioridades son pobreza cero, derrotar al narcotráfico y unir a los argentinos» (1o de diciembre de 2015). Infobae. Recuperado de https://www.infobae.com/2015/12/10/1775652-mauricio-macri-nuestras-prioridades-sonpobreza-cero-derrotar-al-narcotrafico-y-unir-los-argentinos

Norzagaray, M. (2010). El narcotráfico en México desde el discurso oficial (Tesis de maestría). Facultad Latinoamericana de Ciencias Sociales (FLACSO) Sede Académica México. Ciudad de México, México. Recuperado de http://repositorio.flacsoandes.edu.ec/bitstream/10469/2796/1/TFLACSO-201oMDNL.pdf Observatorio de Prevención del Narcotráfico (OPRENAR). (2015). Propuestas de Políticas Públicas Integrales para la Prevención del Avance del Narcotráfico. Recuperado de https://oprenar.files.wordpress.com/2015/10/oprenar-propuestasprevenciczb3n-narcotrczanfico-bw.pdf

Orsini, M. M. (2015). Media Narratives and Drug Prohibition: A Content Analysis of Themes and Strategies Promoted in Network News Coverage, 2000-2013 (Theses, Dissertations and Capstones). Paper 913. Recuperado de https://mds.marshall.edu/cgi/viewcontent.cgi?referer=https://www.google.com.ar/\&http sredir $=1 \&$ article $=1918 \&$ context $=$ etd

Rosen, J. y Zepeda Martínez, R. (2016). La Guerra contra las Drogas y la Cooperación internacional: el caso de Colombia. Revista C S, (18), 63-84.

https://doi.org/10.18046/recs.i18.1848 
Salaverría, R. y Cores, R. (2005). Géneros periodísticos en los cibermedios hispanos. En R. Salaverría (Coord.), Cibermedios. El impacto de internet en los medios de comunicación en España (pp. 145-185). Sevilla, España: Comunicación Social Ediciones y Publicaciones. Recuperado de https://dadun.unav.edu/bitstream/10171/7284/1/cap5_generos_ciberperiodisticos_en_lo s_cibermedios_hispanos.pdf

Sivak, M. (2013). Clarín, el gran diario argentino. Una historia. Ciudad Autónoma de Buenos Aires, Argentina: Planeta.

United Nations Office on Drugs and Crime (UNODC). (2003). Los tratados de fiscalización internacional de drogas. Recuperado de https://www.unodc.org/documents/commissions/CND/Int_Drug_Control_Conventio ns/Ebook/The_International_Drug_Control_Conventions_S.pdf

United Nations Office on Drugs and Crime (UNODC). (2009). Declaración Política y Plan de Acción sobre cooperación internacional en favor de una estrategia integral y equilibrada para contrarrestar el Problema Mundial de las Drogas. Nueva York, Estados Unidos: Organización de Naciones Unidas. Recuperado de https://www.unodc.org/documents/commissions/CND/CND_Sessions/CND_52/Political -Declaration2009_Vo984966_S.pdf

Vázquez, J. (2011). La sombra del narcotráfico. Una amenaza global.

Ciudad Autónoma de Buenos Aires, Argentina: Capital Intelectual.

Verón, E. (2005). Fragmentos de un tejido. Barcelona, España: Gedisa.

\section{Fuentes analizadas}

No pasó de Formosa. Un viaje de 3.000 kilómetros con droga en latas de durazno (11 de febrero de 2016). Clarín. Recuperado de https://www.clarin.com/policiales/viajekilometros-droga-latas-durazno_o_4k-TrRBcl.html

Operativos en Hurlingham. Secuestran armas, cocaína y marihuana en 10 allanamientos simultáneos (2 de julio de 2016). Clarín. Recuperado de https://www.clarin.com/policiales/secuestran-cocaina-marihuana-allanamientossimultaneos_o_B1yzb5BI.html 
Messi, V. (30 de abril de 2016). Cayó en Belgrano: «Rodrigo», el narco mexicano que amaba las Harley-Davidson. Clarín. Recuperado de https://www.clarin.com/policiales/Rodrigo-narco-mexicano-amaba-HarleyDavidson_o_NiovcChxb.html

López, V. (4 de noviembre de 2016). Prevención e investigación, los ejes para combatir la droga. Clarín. Recuperado de https://www.clarin.com/sociedad/Prevencioninvestigacion-ejes-combatir-droga_o_rJIihLcgl.html

Con sello mafioso. Otra muerte narco en Rosario: asesinaron a balazos a una joven que vendía droga en la calle (8 de octubre de 2016). Clarín. Recuperado de https://www.clarin.com/policiales/muerte-rosario-asesinaron-balazosvendia_o_HJow7YIR.html

Messi, V. (2 de octubre de 2016). Cinco detenidos: Cae una banda que traficaba armas y drogas desde la villa 1-11-14: tenían un arsenal. Clarín. Recuperado de https://www.clarin.com/policiales/cae-traficaba-drogas-villa-arsenal_o_HJ4-BeJC.html

Tucumán: Encuentran 55 kilos de cocaína escondidos en bolsas de ajíes (15 de noviembre de 2016). Clarín. Recuperado de https://www.clarin.com/policiales/encuentran-cocaina-escondidos-bolsasajies_o_SyLVpud-g.html

Cada vez más droga: el secuestro de éxtasis creció un 600 por ciento respecto a 2015 (15 de diciembre de 2016). Clarín. Recuperado de https://www.clarin.com/policiales/secuestro-extasis-crecio-cientorespecto_o_ByRxVoxNl.html

Desde la clandestinidad, el concejal acusado de narco dice que «es una cama» (25 de diciembre de 2016). Clarín. Recuperado de https://www.clarin.com/policiales/clandestinidad-concejal-acusado-narcocama_o_41PejUh9x.html

Gallotta, N. (11 de abril de 2016). Llegó de España engañado por traficantes: La trágica historia de la «mula» que murió sin saber lo que hacía. Clarín. Recuperado de https://www.clarin.com/policiales/tragica-historia-mula-muriosaber_o_EJiEZa7Jb.html 
Denuncia: PPT reveló más conexiones entre Aníbal Fernández y tres casos

de narcotráfico (10 de julio de 2016). Clarín. Recuperado de

https://www.clarin.com/politica/ppt-conexiones-anibal-fernandez-

narcotrafico_o_rkBieFlw.html

\section{Notas}

1 La tesis de la que se desprende este artículo, dirigida por el Dr. César Luis Díaz, fue defendida y aprobada en 2020.

2 Mauricio Macri asumió la Presidencia de la República Argentina el 10 de diciembre de 2015.

3 El 10 de diciembre de 2015, Mauricio Macri asumió la Presidencia de la República Argentina y, en ese contexto, mencionó los tres pilares de su gobierno que quedaron reflejados en el titular de Infobae: «Nuestras prioridades son pobreza cero, derrotar al narcotráfico y unir a los argentinos» (10/12/2015).

4 Se alude a los documentos Convención Única de 1961 sobre Estupefacientes (enmendada por el Protocolo de 1972), Convenio sobre Sustancias Sicotrópicas, de 1971, y Convención de las Naciones Unidas contra el Tráfico Ilícito de Estupefacientes y Sustancias Sicotrópicas, de 1988 (UNODC, 2003).

5 Que ratifica lo expresado en la «Declaración Política de la Asamblea General de las Naciones Unidas» (1998).

6 Prodestinatario, aquel destinatario que siente cierto grado de identificación con la información $\mathrm{y}$, de esta forma, refuerza la creencia compartida; paradestinatario, aquel destinatario indeciso respecto de la idea que se plantea en la información; antidestinatario, aquel destinatario contrario a la idea que se desarrolla en la información (Verón, 1995).

7 Estos procesos son explicitados en el libro de SEDRONAR, Centros de procesamiento ilícito de estupefacientes en Argentina (Donzelli \& Souto, 2011).

8 Alexa.com es «una de las plataformas más fiables y concurridas para conocer el número de visitas que tiene una web [...]. Alexa Internet es una subsidiaria de la compañía Amazon.com que tiene base en California, conocida por operar en el sitio web alexa.com, que ofrece información acerca de la cantidad de visitas que recibe una web determinada. La página establece rankings de las webs más visitadas en función de la media de visitas del último mes, lo que permite generar estadísticas a partir del número de visitas y de los enlaces relacionados (García, 2011, p. 139). 
9 Otro ranking que identifica los medios de comunicación con mayores venta, pero que no cumple con los requisitos necesarios para la presente investigación, se encuentran disponible en http://www.prensaescrita.com/america/buenosairescf.php

10 Las tesis «Media Narratives and Drug Prohibition: A Content Analysis of Themes and Strategies Promoted in Network News Coverage, 2000-2013» (Orsini, 2015) y «El narcotráfico en México desde el discurso oficial» (Norzagaray 2010), junto con los artículos «Illicit Drugs and the Media: Models of Media Effects for Use in Drug Policy Research» (Lancaster y otros, 2010) y «El narcotráfico analizado. Un recorrido por las principales características del tráfico ilícito de estupefacientes en Argentina según la literatura especializada» (Collinao, Vázquez y otros, 2015), constituyeron fuentes de consulta constante durante la redacción de estas líneas.

11 Albornoz (2005) indica que la hemeroteca digital del diario Clarín permite consultar contenidos a partir del 18 de marzo de 1996 (parcialmente) y las «Ediciones Anteriores» (a través de una ventana emergente). El autor señala, también, que se pueden consultar ediciones del diario impreso, en formato PDF, desde el 2 de enero de 2003.

12 En 2008 se descubrió una «cocina» de drogas sintéticas en la localidad bonaerense de Maschwitz, caso que se conoció como «la casa de cristal de Maschwitz». Este hecho marcó el inicio de una serie de investigaciones paralelas, cuyos resultados -siempre enmarañados- denotaban un estrecho vínculo entre ciudadanos mexicanos y argentinos que trabajaban en connivencia en lo que popularmente se conoció como «la ruta de la efedrina», es decir, el tráfico ilegal de este precursor químico.

13 Damián Ferrón, Sebastián Forza y Leopoldo Bina fueron secuestrados y asesinados en agosto de 2008. Sus cuerpos fueron escondidos durante una semana y luego hallados -con claras señales de haber sido torturados- en un campo de la localidad bonaerense de General Rodríguez. El caso tiene estrecha relación con el tráfico ilegal de efedrina a México, una sustancia preciada por los carteles narco de ese país. En la Argentina, el asesinato cobró relevancia por posibles aportes económicos a la campaña de Cristina Fernández durante 2007 y otro hecho popularmente conocido como «mafia de los medicamentos». Si bien Cristian Lanatta, Martín Lanatta, Víctor Schilacci y Marcelo Schilacci fueron detenidos y condenados a cadena perpetua, las familias de las víctimas consideran que no fueron los autores intelectuales de los asesinatos.

14 Adjetivado por la prensa como el «jefe del cartel mexicano de la efedrina» (Collinao, Vázquez y otros, 2015).

15 Cabe señalar que Clarín no utilizó el recurso del hipertexto para hacer referencia a publicaciones sobre el incendio. 
16 En el capítulo «El odio y la mentira. Los nuevos medios y los mismos fines», del libro Sinceramente, de Cristina Fernández de Kirchner, se relata un hecho similar en el que el mismo programa menciona la existencia de bóvedas y de cajas fuertes en la propiedad de la ex Presidenta, pero no ofrece evidencia real sino que presenta maquetas de cómo eso sería, a fin de crear en su audiencia una percepción de veracidad y de presentar sus investigaciones como un trabajo serio.

17 Vinculados al FPV y también llamados de este modo por adherir a las ideas de los líderes del partido, Néstor Kirchner y Cristina Fernández de Kirchner.

18 Se consideran aquí, las palabras de Sivak (2013), quien indica que, desde 2005, Clarín solo capitalizó a lectores antikirchneristas.

19 «Tiene todos los elementos: importación (de marihuana, cocaína y droga sintética), transporte, logística, lugares de acopio, distribución mayorista, distribución minorista (el llamado narcomenudeo) y exportación (fundamentalmente de cocaína)» (López, 04/11/2016). 